\title{
Experimental Study of Chemical Flooding of Suizhong 36-1 Oilfield
}

\author{
Pi Yanfu ${ }^{1, *}$, Guo Xiaosai ${ }^{2}$, Pi Yanming ${ }^{3}$ and Wu Peng ${ }^{4}$
}

\author{
${ }^{I}$ Northeast Petroleum University, Daqing, Heilongjiang, 163318, P.R. China $;{ }^{2}$ Northeast Petroleum University, Daqing, \\ Heilongjiang, 163318, P.R. China; ${ }^{3}$ CNOOC Energy Development Company Limited, Tianjin, 300000, P.R. China; \\ ${ }^{4}$ Bohai Oilfield Research Institute of CNOOC Ltd, Tianjin, 300452, P.R. China
}

\begin{abstract}
Aim at the reservoir characteristics of Suizhong 36-1 Oil Field, this paper has developed typical twodimensional physical model in parallel between the layers and studied the macroscopic displacement effect of polymer flooding and binary compound flooding, and studied the interlayer spread law and oil displacement efficiency of polymer flooding and binary combination flooding by using saturation monitoring system deeply. The results show that: when the multiples of pore volume injected for polymer was 0.3 after water flooding, the recovery efficiency increased by $10.3 \%$, and when the multiples of pore volume injected for binary combination flooding was 0.3 after polymer flooding and the recovery efficiency could also increase by $19.3 \%$, and the effect of enhanced oil recovery was obvious during the binary combination flooding and polymer flooding; Saturation monitoring data showed that there formed oil wall and increased the flow resistance and expanded the swept volume during the stage of polymer flooding and binary combination flooding, effective use of low-permeability layer was the key to improve oil recovery.
\end{abstract}

Keywords: Chemical flooding, enhanced oil recovery, oil saturation, swept law, oil displacement efficiency.

\section{INTRODUCTION}

The sustained growth of offshore oil production has become an important part of oil production capacity to replace, it is imperative to develop the enhanced oil recovery technology of offshore with the increasing difficulty of exploration and efficient development of oil and gas resources in offshore [1,2]. All kinds of chemical flooding technology have become more mature especially the large-scale industrial application of polymer flooding with the successful implementation of chemical flooding in onshore oilfield. Chemical flooding technology has been gradually developed to offshore oilfield whose reservoir is complex and injection conditions are harsh and risk characteristics is high [3-5]. As the most potential chemical flooding technology, polymer flooding and binary combination flooding have become the first displacement way after water flooding in the offshore oil field, it is essential to research the ways and the effect of these two kinds of chemical flooding in offshore oilfield, which could provide the basis of exploration adjustment of oilfield, due to the complex reservoir conditions, the high temperature, hyper salinity, crude with oil high viscosity and the high cost of the implementation of chemical flooding[68]. Aim at the present conditions of reservoir and the situation of exploitation in Suizhong 36-1 oilfield [7-9], this paper has used the binary combination system which is formulated by AP-P5 polymer and BHM2 surfactant to compare the flooding effect of binary combination flooding after polymer flooding and the exploitation curve and the change law of the saturation field through the comparative experiments of parallel physical simulation by the physical model which with three unequal thickness heterogeneity.

\section{EXPERIMENT PART}

\subsection{The Method of Saturation Monitoring}

Saturation monitoring literature shows that the rock electricity experiment is the widest method to monitor oil saturation whose theoretical basis is Archie, the function relation between the resistivity of the two points of the reservoir rock, and the moisture content is the core idea and the oil saturation can be determined judged by the resistivity after finds the relations $[10,11]$.

This paper adopts the oil saturation monitoring technology based on the above theory; real-time monitoring to the oil saturation of electrode which lay in the two-dimensional physical model in the process of experiment by the real-time monitoring system, the electrodes which were arranged and divided the two-dimensional physical model into different grid. It can grasp the spread situation of the monitoring points through the change of oil saturation [12-14]. The oil saturation is lower than the initial value monitoring points at the end of a displacement stage which was believed that point is affected and the displacement efficiency data can be calculated combined with macroeconomic recovery.

\subsection{The Experimental Conditions and the Experimental Scheme}

The experimental water is the simulated formation water of offshore oil whose salinity is $9374 \mathrm{mg} / \mathrm{L}$; The experimental oil is the simulation oil which is mixed with crude oil and kerosene oil and the viscosity is $70 \mathrm{mPa} \cdot \mathrm{s}$ when the tempera- 
Table 1. Results of enhanced oil recovery at different displacement stage.

\begin{tabular}{|c|c|c|c|c|}
\hline & \multicolumn{3}{|c|}{ The degree of recovery in the inner layer } & \multirow{2}{*}{$\begin{array}{l}\text { The whole } \\
\text { model (\%) }\end{array}$} \\
\hline & $\begin{array}{c}\text { Low permeability layer } \\
(\%)\end{array}$ & $\begin{array}{l}\text { Middle permeability } \\
\text { layer }(\%)\end{array}$ & $\begin{array}{l}\text { High permeability layer } \\
\qquad(\%)\end{array}$ & \\
\hline water flooding until the moisture content is $70 \%$ & 4.5 & 15.8 & 23.6 & 18.0 \\
\hline water flooding until the moisture content is $95 \%$ & 4.5 & 17.4 & 40.2 & 26.2 \\
\hline Polymer flooding stage & 5.7 & 16.2 & 25.2 & 36.5 \\
\hline binary flooding stage & 22.1 & 24.3 & 15.5 & 19.3 \\
\hline The total recovery & 32.3 & 56.3 & 64.3 & 55.5 \\
\hline
\end{tabular}

ture is $65{ }^{\circ} \mathrm{C}$; The physical model which are used in the experiment are quartz sand epoxy cemented heterogeneous saturation monitoring cores whose specifications are $300 \times$ $300 \times 30 \mathrm{~mm}$ and electrodes are arranged different permeable layer and permeability of each layer is respectively 4800 , $2200,500 \times 10-3 \mu \mathrm{m} 2$; The polymer used in the experiments in polymer flooding stage is AP-P4 hydrophobic associative polymer whose concentration is $2000 \mathrm{mg} / \mathrm{L}$ and the viscosity is $42 \mathrm{mPa} \cdot \mathrm{s}$; Binary combination stage with AP - P5 hydrophobic associating polymer with the concentration of $1750 \mathrm{mg} / \mathrm{L}$, mass concentration of BHM surfactant 2 is $0.2 \%$ and the viscosity is $34.5 \mathrm{mPa}$, s; The experimental temperature are conducted under the condition of $65{ }^{\circ} \mathrm{C}$; The injection speed: $3 \mathrm{ml} / \mathrm{min}$. The experiment adopts the form of parallel and the experimental diagram is as shown in Fig. (1).

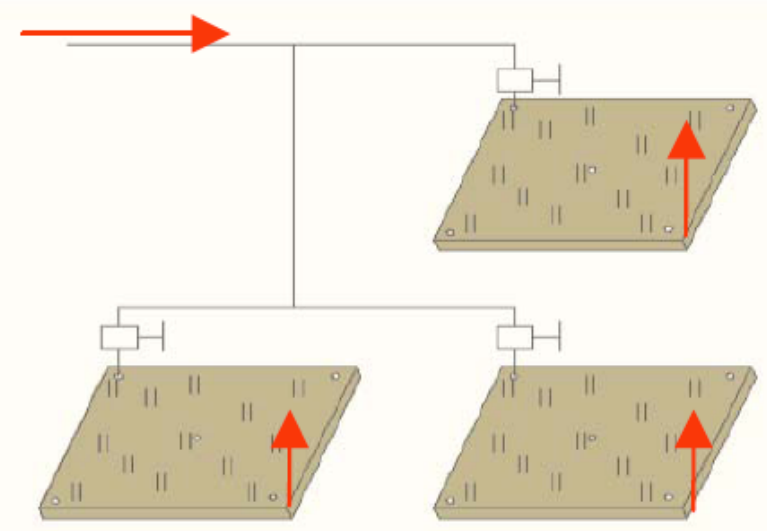

Fig. (1). Schematic diagram of parallel displacement experiment. $95 \%$;

Scheme one: water flooding until the moisture content is

Scheme two: water flooding until the moisture content is $70 \%+0.3 \mathrm{PV}$ polymer flooding + subsequent water flooding until the moisture content is $95 \%$;

Scheme three: water flooding until the moisture content is $70 \%+0.3 \mathrm{PV}$ polymer flooding $+0.3 \mathrm{PV}$ binary (APP5 + BHM2) + Subsequent Water Flooding until the moisture content is $95 \%$.

The concept of PV is the multiples of pore volume injected.

\subsection{The Experimental Results and Analysis}

(1) The overall results of different displacement scheme

As can be seen from Table $\mathbf{1}$, the overall recovery rate is $18 \%$ when the moisture content is $70 \%$ during the water flooding in scheme one and the low permeability layer is no longer being used and recovery rate of the middle permeability layer increased only $1.6 \%$ and the recovery rate of overall increased by $8.2 \%$ after water flooding to the moisture content is $70 \%$. The overall recovery is $36.2 \%$ when injection $0.3 \mathrm{PV}$ polymer before subsequent water flooding to the moisture content of $95 \%$ in scheme two and the overall degree of recovery increased by $10.3 \%$ compared with scheme one. The scheme three is injection $0.3 \mathrm{PV}$ binary after polymer flooding and then subsequent water flooding which the overall recovery of $55.5 \%$. As we can seen from the result: binary solution can greatly improve the recovery efficiency in inner layer of low medium high permeability layer, binary solution can use the area where the polymer flooding insufficient coverage and carry the oil droplets and oil film which were remnants in the core porosity by the ultra-low interfacial tension and the strong emulsification, it can reduce the difficulty of exploitation from the two aspects which are expanding sweep efficiency and enhance oil displacement efficiency and greatly improve the overall recovery rate.

(2) Dynamic mining curve and analysis of each scheme

1) Dynamic mining characteristics and analysis of water flooding

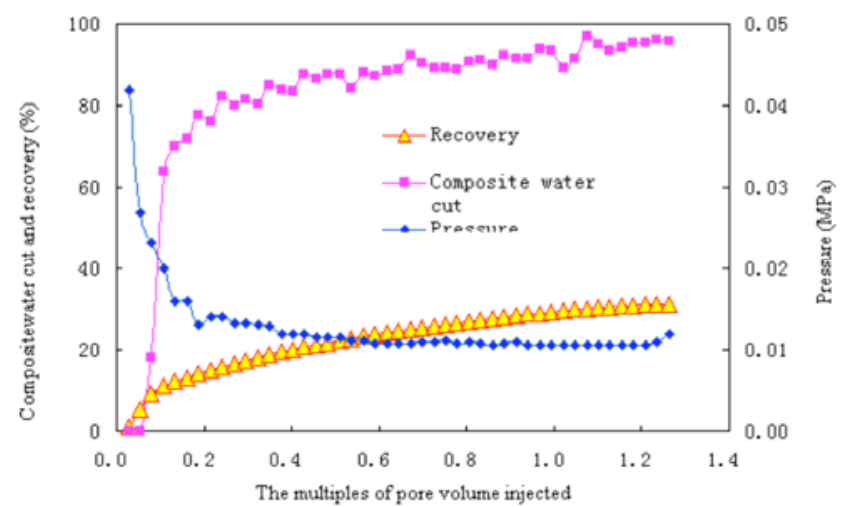

Fig. (2). Relation curve between the multiples of pore volume injected and composite water cut, recovery and pressure. 


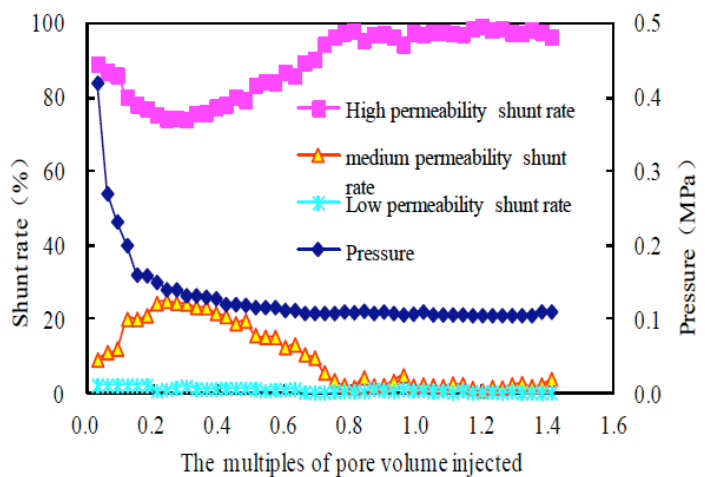

Fig. (3). Relation curve between the multiples of pore volume injected and shunt rate and pressure.

As you can see from Fig. (2) and Fig. (3): pressure suddenly increased at the beginning of water flooding, pressure drops rapidly with the increase of water injection, the moisture content increased rapidly at the beginning and the moisture content began to rise slowly when the moisture content reached to $70 \%$ in the whole process and the injection pressure also decreased slowly and gradually closed to be stable. Absorption of high permeability layer was very high which mainly because the small flow resistance, large thickness, large pore volume of high permeability made the layers liquid easy to access.

2) Dynamic mining characteristics and analysis of polymer flooding

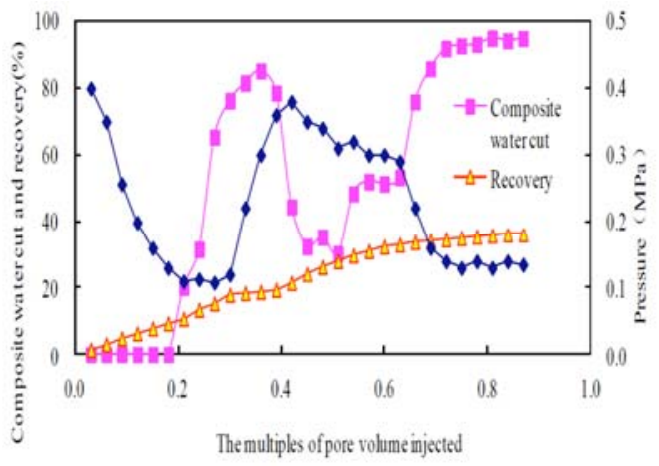

Fig. (4). Relation curve between the multiples of pore volume injected and composite water cut, recovery and pressure.

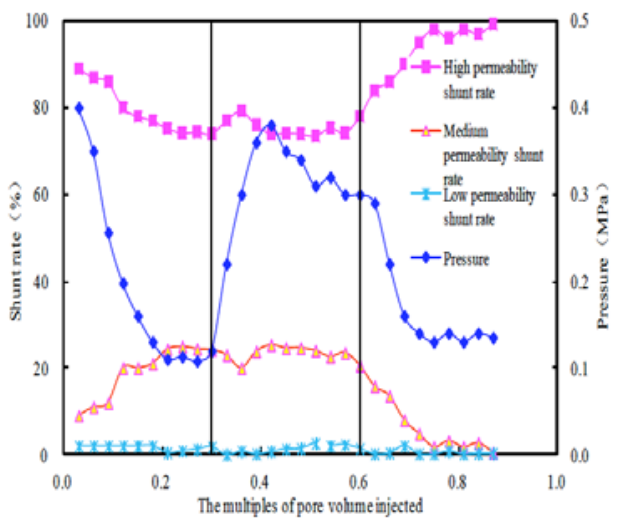

Fig. (5). Relation curve between the multiples of pore volume injected and shunt rate and pressure.
As can be seen from Fig. (4) and Fig. (5): polymer injection started when the moisture content is $70 \%$ during the water polymer injection and the integrated water content first increased and then decreased due to the lag effect of polymer. The pressure began to rise and the diversion rate of high permeability layers began to decline and diversion rates of low permeability layer gradually increased with the gradual injection of the polymer. The pressure began to decline, pressure quickly reduced stable volatility in a nearby value as the mainstream of high permeability channel was completely open, then the diversion rate of high permeability layer reached more than $90 \%$ while the diversion rate was very small of the low-permeability layer and hardly has the liquid to enter in the subsequent water flooding stage.

3) Dynamic mining characteristics and analysis of binary flooding

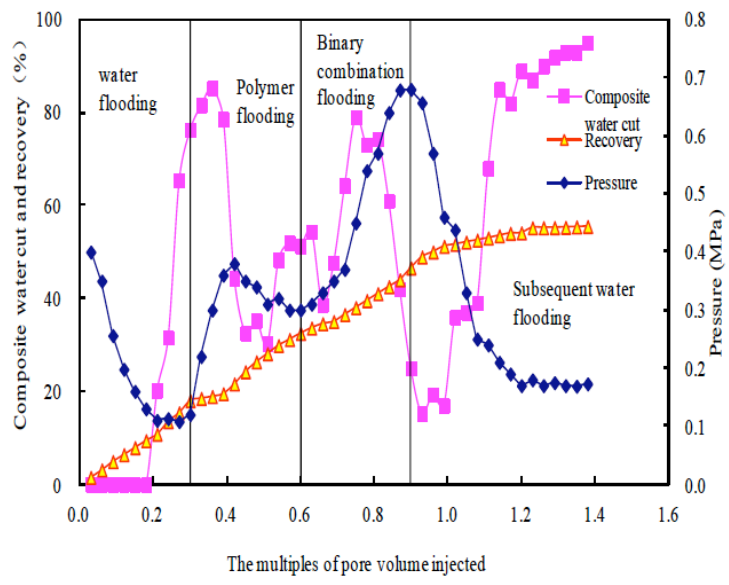

Fig. (6). Relation curve between the multiples of pore volume injected and composite water cut, recovery and pressure.

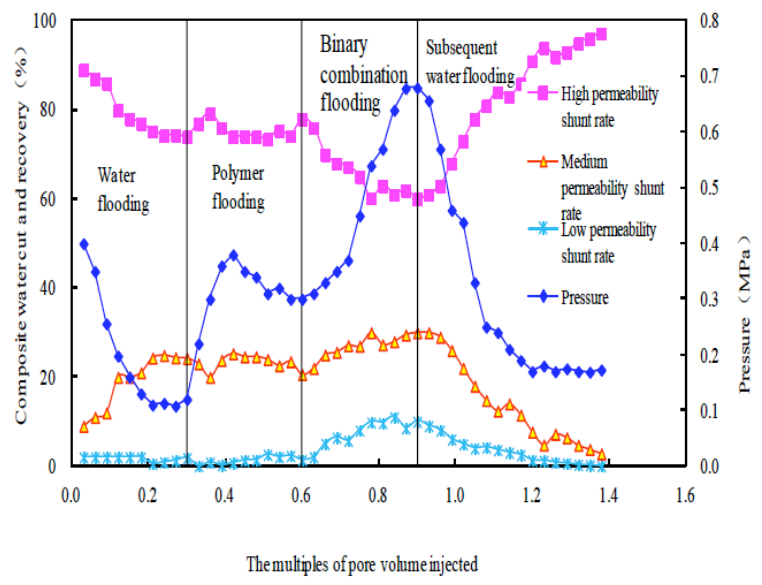

Fig. (7). Relation curve between the multiples of pore volume injected and shunt rate and pressure.

As you can see from Fig. (6) and Fig. (7), the pressure gradually increased and the moisture content reduced substantially after injection the binary solution, this is because there is (a large oil wall was displacement to outlet end which formed in the core, the moisture content began to rise and the shunt rate of low and medium permeability in binary combination stage obviously raised with the oil wall was 
gradually displacing recovery, which indicated that a substantial increase of swept volume in binary flooding and the low and medium permeability layer were used effectively. The shunt rate of high permeability rose gradually, and the low and medium permeability's gradually decreased, the minimum value of comprehensive water content was emerged at the end of binary combination flooding in the stage of Subsequent water flooding. The enhanced recovery rate changed gradually slowly in the whole process of displacement, which illustrated that the difficulty of mining gradually increased.

(3) Oil saturation distribution of each permeability layer under the flooding of polymer and binary combination

1) Polymer flooding stage

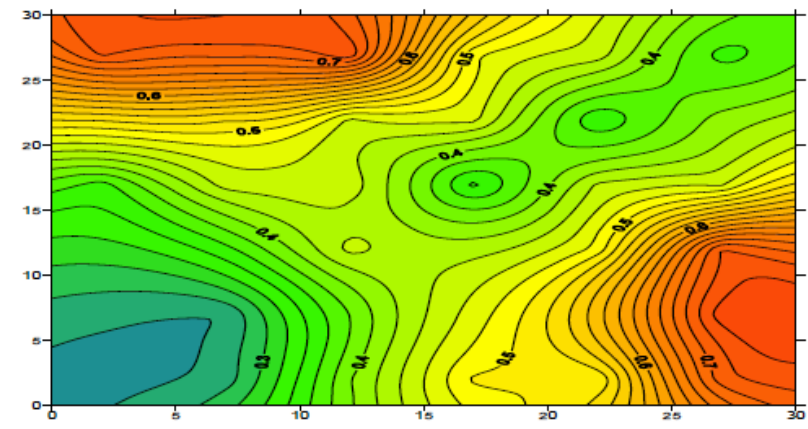

The high permeability layer

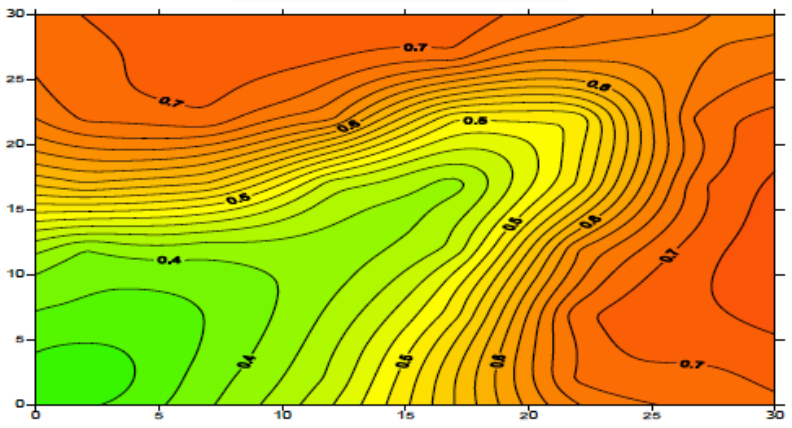

The medium permeability layer

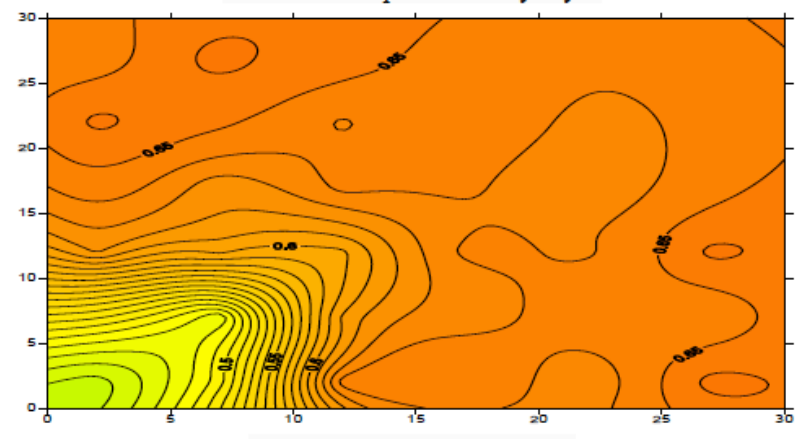

The low permeability layer

Fig. (8). Distribution of oil saturation of each layer at initial polymer flooding phase.

As can be seen from Fig. (8): the polymer which was first injected into the mainstream line of high permeability layer and drove the portion droplets which on the mainstream line move forward, the polymer molecule can move and displace the oil film to the recovery wells which the part that water flooding could not drag and drop due to the polymer molecule itself had certain elasticity and strong stretching deformation, thereby it increased the efficiency of wash oil of mainstream lines in the high permeability layer. There was an oil wall obviously emerging in the high permeability layer at the end of the initial polymer injection, at this time pressure rose quickly due to the high viscosity of polymer and the sealing effect of the oil wall, portion of the pore throats of the low-permeability layer also reached the required startup pressure, then the swept area began to be expanded gradually in the medium permeability layer and the oil saturation near the injection wells gradually reduced and a large area of low permeability layer also began to be used.

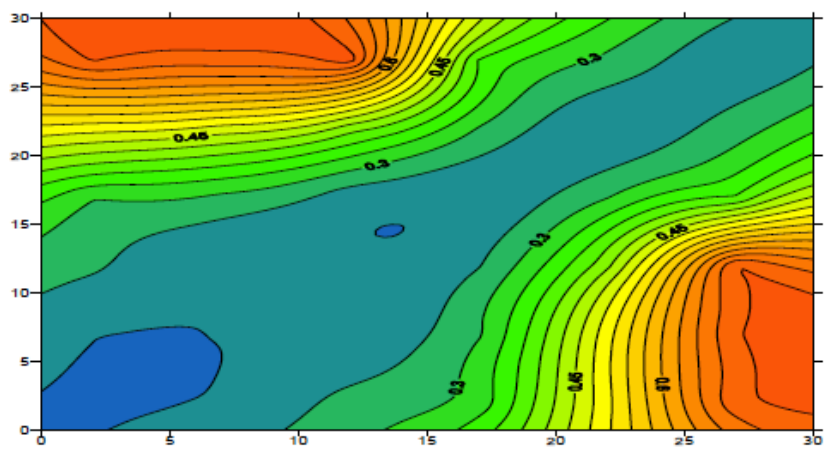

The high permeability layer

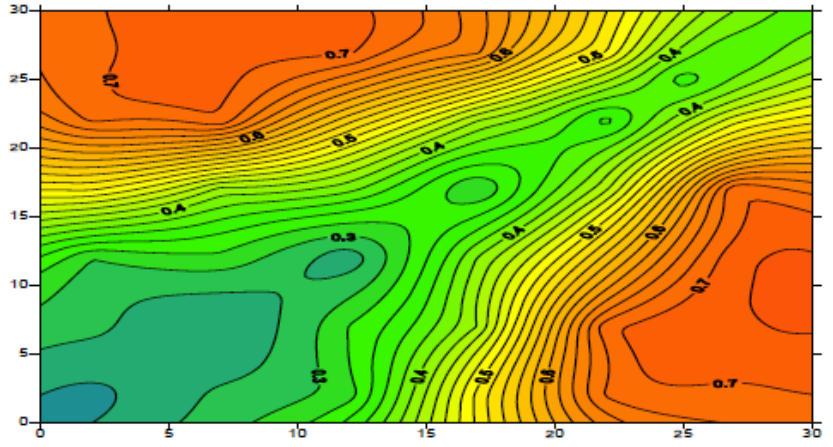

The medium permeability layer

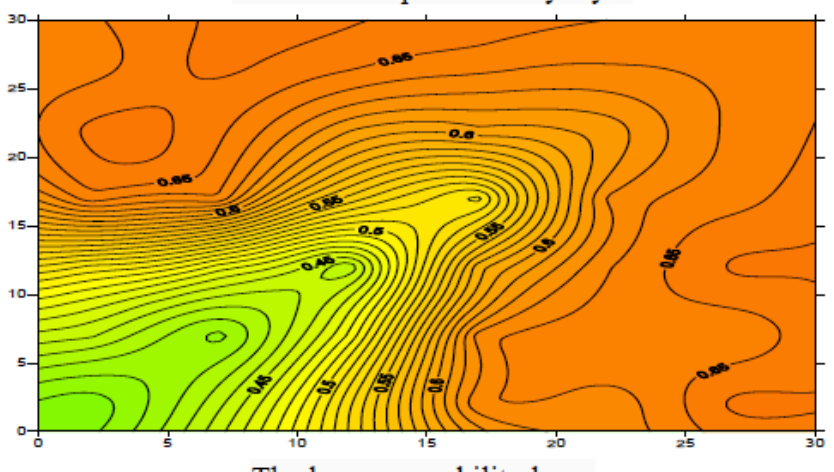

The low permeability layer

Fig. (9). Distribution of oil saturation of each layer at the end of polymer flooding.

As can be seen from Fig. (9): the area near the mainstream line and the mainstream line in the high permeability layer opened again after injection polymer at a period of time; The mainstream line in the medium permeability layer gradually formed a complete channel; low permeability layer 
near the injection well was also used due to the increase of pressure, pressure dropped rapidly, low permeability layer would not be used anymore after the mainstream line was breakthrough in high permeability layer.

2) Binary combination flooding stage

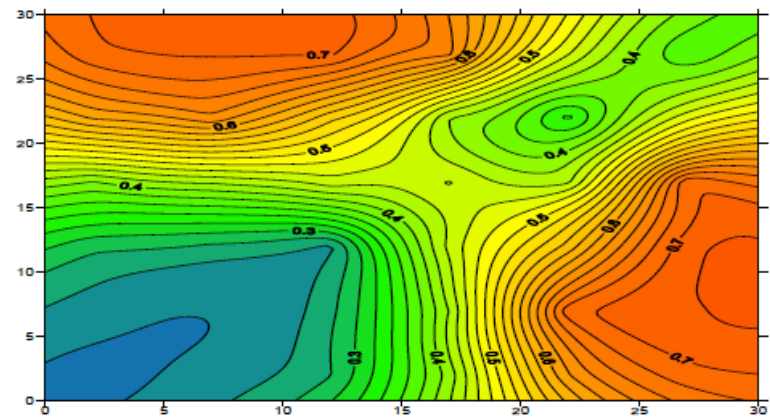

The medium permeability layer

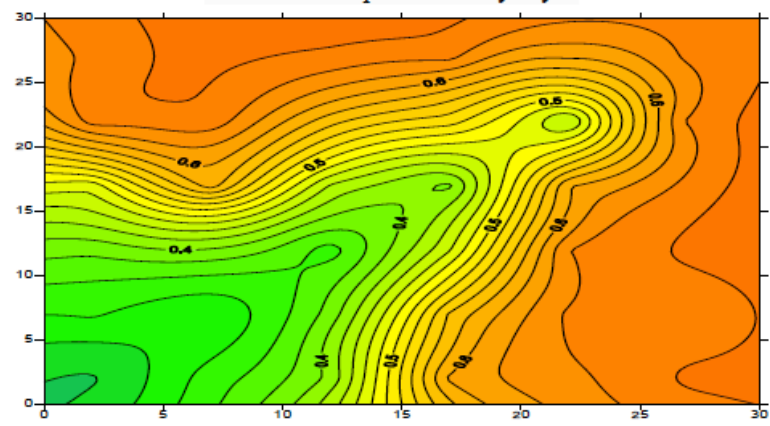

The low permeability layer

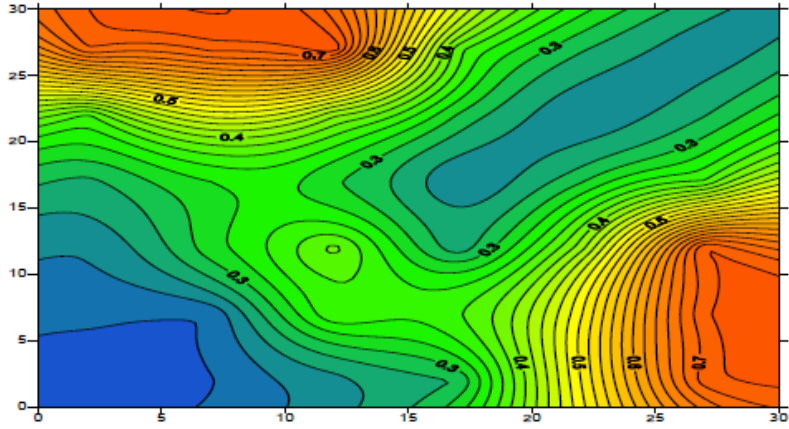

The high permeability layer

Fig - (10). Distribution of oil saturation of each layer at initial binary flooding phase.

As can be seen from Fig. (10): the binary solution first went into the high permeability layer which has a relatively small resistance at the beginning of injection binary solution emulsion and pushed forwards the oil droplets which the residual in the mainstream that did not use in the polymer flooding by its emulsification, the resistance of cores and the injection pressure increased due to the plugging and mobile, so a large amount of solution of binary went into the medium and low permeability layer. The oil walls were gradually formed in different permeability layers and the effect of enlarges swept volume in the low and medium permeability was obvious in the stage of injection binary solution.
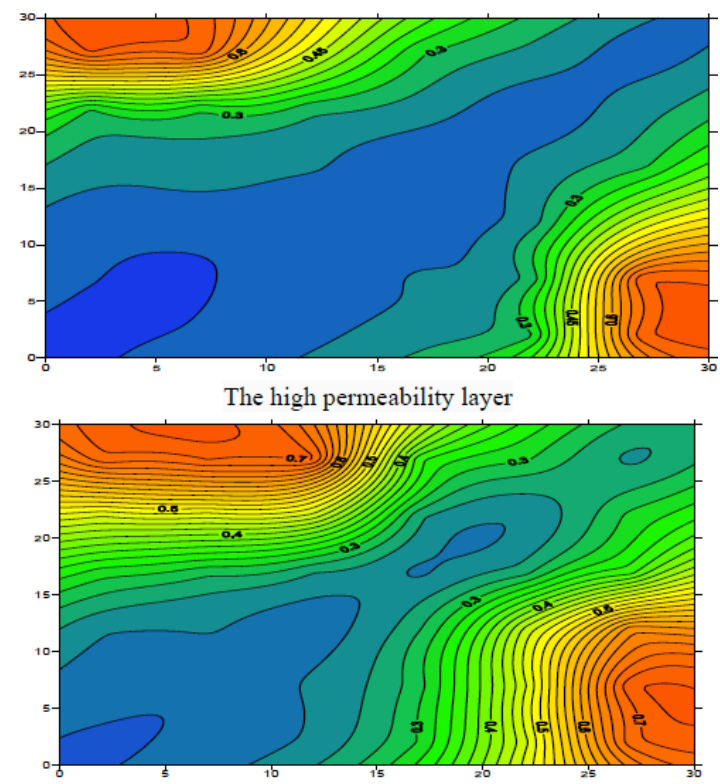

The medium permeability layer

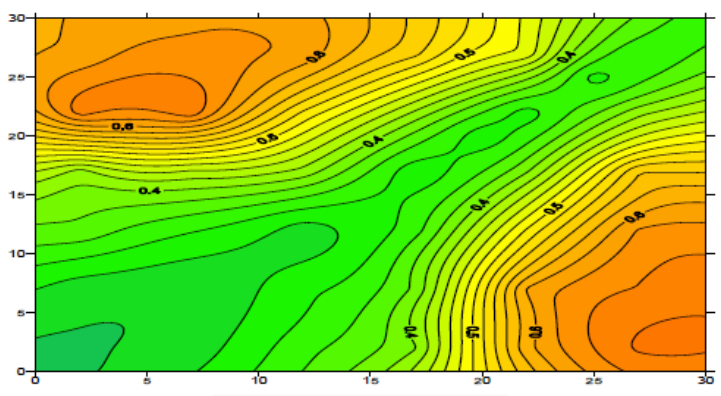

The low permeability layer

Fig. (11). Distribution of oil saturation of each layer at the end of binary combination flooding.

The oil saturation distribution which at the end of subsequent water flooding after binary flooding scheme is as shown in Fig. (11), the mainstream line had been broke through and there were lots of remaining oil in low and medium permeability layer at the end of the subsequent water flooding.

Table 2. Results of sweep efficiency and oil displacement efficiency in different scheme.

\begin{tabular}{|c|c|c|c|c|c|}
\hline Parameter & Scheme & $\begin{array}{c}\text { The low } \\
\text { permeability } \\
\text { layer }\end{array}$ & $\begin{array}{c}\text { The medium } \\
\text { permeability } \\
\text { layer }\end{array}$ & $\begin{array}{c}\text { The high } \\
\text { permeability } \\
\text { layer }\end{array}$ & $\begin{array}{c}\text { The } \\
\text { whole }\end{array}$ \\
\hline \hline \multirow{2}{*}{$\begin{array}{c}\text { Sweep } \\
\text { efficiency } \\
(\%)\end{array}$} & 1 & 13.0 & 41.0 & 90.1 & 48.0 \\
\cline { 2 - 6 } & 2 & 37.5 & 67.0 & 90.5 & 65.0 \\
\cline { 2 - 6 } & 3 & 77.0 & 86.7 & 94.4 & 87.4 \\
\hline \multirow{2}{*}{$\begin{array}{c}\text { Oil dis- } \\
\text { placement } \\
\text { efficiency } \\
(\%)\end{array}$} & 1 & 46.3 & 51.5 & 62.2 & 63.2 \\
\cline { 2 - 6 } & 2 & 40.3 & 53.7 & 64.2 & 59.4 \\
\hline \multirow{2}{*}{\begin{tabular}{c} 
(\%) \\
\cline { 2 - 6 }
\end{tabular}} & 41.9 & 64.9 & 68.1 & 63.5 \\
\hline
\end{tabular}


We can obtain the displacement situation of each scheme by statistical calculation (Table 2), water flooding mainly used in the high permeability layer as we can be seen the sweep efficiency was as high as $90.1 \%$. The sweep efficiency of low, medium and high permeability layer on the basis of water flooding were improved which increased by $20 \%$ at the end of polymer flooding. The sweep efficiency of high permeability layer increased only $0.4 \%$. Each permeability layers had high sweep efficiency after the polymer flooding after binary combination flooding. The above analysis shows that the polymer mainly expands sweep efficiency of medium and low permeability layer and enhances oil displacement efficiency in the high permeability layer). There is higher oil displacement efficiency during the binary combination flooding, so the binary multisystem could greatly enhance oil recovery.

\section{CONCLUSION}

(1) The parallel experiment of two-dimensional flat core of typical block in offshore oilfield shows that: injection 0.3 PV polymers after water flooding can improve the recovery rate by $10.3 \%$, and injection 0.3 PV binary multisystem after polymer flooding can also improve the recovery rate by $19.3 \%$, binary combination flooding can dramatically improve recovery after polymer flooding.

(2) Saturation monitoring experiments show that: oil wall was formed which increased the flow resistance in the phase of polymer flooding and binary combination flooding, the shunt rate of medium and low permeability layer became large. Enlarging swept volume played an important role in enhanced oil recovery for polymer and binarycombination flooding, mainly used in middle and low permeability layer and achieved a substantial increase in oil recovery.

(3) Polymer flooding after water flooding was carried out in Suizhong 36-1 offshore oil field which improved the recovery rate over $10 \%$, binary compound flooding was an effective mining way after polymer flooding and the potential of improving recovery was above $19 \%$. We can take the form of infill wells to mine according to the actual saturation distribution in the process of binary combination flooding.

\section{CONFLICT OF INTEREST}

The authors confirm that this article content has no conflict of interest.

\section{ACKNOWLEDGEMENTS}

This work was supported together by China National Major Projects "Reservoir Research for Enhanced Oil Recovery Technology after Polymer Flooding in Offshore Oilfields" and the open topic "The research of seepage field and pressure field distribution.

\section{REFERENCES}

[1] Z. Wang, and X. Wang, "The key technology to enhance oil recovery of binary compound flooding of offshore oilfield", Petroleum Geology and Recovery Efficiency, vol. 21, pp. 5-6, 2014.

[2] C. Wang, Potential Assessment of Enhanced Oil Recovery in Polymer Flooding and Taking Offshore -Suizhong 36-1 Oil Field Oilfield as an Example, China Petroleum University, China, 2010.

[3] D. Wang, H. Dong, C. Lv, X. Fu, and J. Nie, "Review of Practical Experience by Polymer Flooding at Daqing", SPE, 114342-PA, 2009.

[4] X. Zhang, E. Tang, X. Xie, and Z. Wei, "Research on development characteristics and injection mode of early polymer injection of offshore oilfield", Journal of Oil and Gas, vol. 35, pp. 123-124, 2013.

[5] K. Li, Study on Formula of Binary Compound Flooding of Offshore Oilfield, China Petroleum University, China 2011.

[6] F. Zhang, J. Wei, F. Sun, and S. Zhou, "Key technology research and field test of polymer flooding of heavy oil of offshore oilfield", China Engineering Science, vol. 13, pp. 28-29, 2011.

[7] Z. Wei, Z. Jian, G. Feng, J. Wei, F. Sun, S. Zhou, and Y. Liu, “Key Technologies of Polymer Flooding in Offshore Oilfield of Bohai Bay", SPE-115240-MS, 2008.

[8] S. Zhou, M. Han, W. Xiang, J. Zhang, Z. Wei, and J. Wei, “Technology research and application of enhance oil recovery of polymer flooding of bohai oilfield", China Offshore Oil and Gas, vol. 18, pp. 386-387, 2006.

[9] J. Gao, Y. Li, J. Li, D. Yin, and H. Wang, "Experimental Study on Optimal Polymer Injection Timing in Offshore Oilfields", OTC, 214, 24694-MS.

[10] H. Ma, J. Li, P. Niu, Z. Hou, and Z. Yang, "Application of dynamic monitoring of reservoir saturation in offshore oilfield", Journal of Oil and Gas, vol. 34, pp. 104-106, 2012.

[11] J. Sun, J. Wu, D. Yu, "Analysis of the influencing factors of archie parameters experiment", Petroleum Geology \& Oilfield Development in Daqing, vol. 25, pp. 39-41, 2006.

[12] C. Yang, H. Li, D. Lu, "The relationship between the saturation and the resistivity of rock in different displacementmodes", Journal of Jilin University (Earth Science Edition), vol. 35, pp. 667-671, 2006.

[13] J. Lin, and Z. Ge, "The calculation method of the original oil saturation of complex reservoir", Petroleum Geology \& Oilfield Development in Daqing, vol. 21, pp. 32-34, 2002.

[14] G. E. Archie, "The electrical resistivity log as an aid in determining some reservoir characteristic", Journal of Petroleum Technology, vol. 146 , no. $1,1942$.

\author{
Received: April 17, 2015 \\ Revised: May 21, 2015 \\ Accepted: May 26, 2015 \\ (C) Yanfu et al.; Licensee Bentham Open.
}

This is an open access article licensed under the terms of the (https://creativecommons.org/licenses/by/4.0/legalcode), which permits unrestricted, noncommercial use, distribution and reproduction in any medium, provided the work is properly cited. 